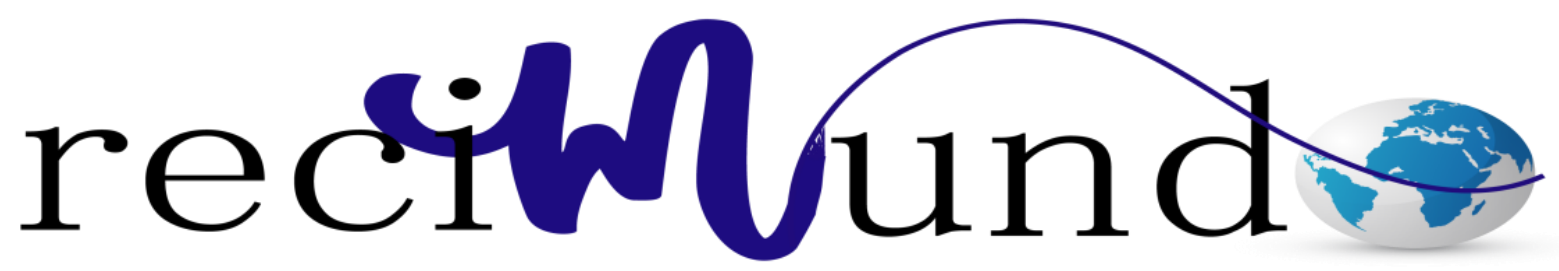

Revista Cientifica Mundo de la Investigación y el Conocimiento

Vinicio Antonio López Del Valle ${ }^{\text {a }}$; Guido Boanerges Troya Moscol ${ }^{\text {b; }}$ Nataly del Roció Varas Landivar ${ }^{c}$; María Belén Guzmán Vega ${ }^{\text {d }}$

Algunas consideraciones sobre el VIH/SIDA

Some considerations on HIV / AIDS

Revista Científica Mundo de la Investigación y el Conocimiento. Vol. 2 núm.4, Octubre, ISSN: 2588-073X, 2018, pp. 48-69

DOI: 10.26820/recimundo/2.(4).octubre.2018.48-69

URL: http://www.recimundo.com/index.php/es/article/view/339

Editorial Saberes del Conocimiento

Recibido: 15/07/2018

Aceptado: 05/08/2018

Publicado: 30/10/2018

Correspondencia: viniciolopez1988@gmail.com

a. Especialista de Primer Grado en Medicina General Integral; Doctor en Medicina; viniciolopez1988@gmail.com

b. Especialista de Primer Grado en Medicina General Integral; Doctor en Medicina; boanerges0685@gmail.com

c. naty23072@hotmail.com

d. oscurabel@yahoo.com 


\begin{abstract}
Algunas consideraciones sobre el VIH/SIDA
Vol. 2, núm. 4., (2018)

Vinicio Antonio López Del Valle; Guido Boanerges Troya Moscol; Nataly del Roció Varas Landivar; María Belén Guzmán Vega
\end{abstract}

\title{
RESUMEN
}

Se realizó una revisión de la literatura relacionada con el VIH/SIDA, enfermedad infectocontagiosa que originó una verdadera pandemia en todo el mundo, con repercusión en el orden biológico, social y económico de magnitudes alarmantes, siendo una preocupación constante para los gobiernos y las autoridades sanitarias. Por tal motivo se consultaron 7 referencias bibliografía con un gran nivel de actualización, lo que permitió que se desarrollaran los aspectos relacionados con los antecedentes, definición, patogenia, fisiopatología, cuadro clínico, diagnóstico, complicaciones y tratamiento, en el que juega un papel importante la prevención al no existir en los momentos actuales un tratamiento curativo de esta afección.

Palabras claves: VIH/SIDA, enfermedad, tratamiento. 


\section{Algunas consideraciones sobre el VIH/SIDA}

Vol. 2, núm. 4., (2018)

Vinicio Antonio López Del Valle; Guido Boanerges Troya Moscol; Nataly del Roció Varas Landivar; María Belén Guzmán Vega

\section{ABSTRACT}

A review of the literature related to HIV / AIDS, an infectious disease that caused a true pandemic around the world, with an impact on the biological, social and economic order of alarming magnitudes, was a constant concern for governments and authorities. sanitary For this reason 7 references were consulted with a high level of updating, which allowed to develop the aspects related to the background, definition, pathogenesis, physiopathology, clinical picture, diagnosis, complications and treatment, in which plays an important role prevention, since there is no curative treatment for this condition at the present time.

Keywords: HIV / AIDS, disease, treatment. 


\section{Algunas consideraciones sobre el VIH/SIDA}

Vol. 2, núm. 4., (2018)

Vinicio Antonio López Del Valle; Guido Boanerges Troya Moscol; Nataly del Roció Varas

Landivar; María Belén Guzmán Vega

\section{Introducción.}

La pandemia producida por el Virus de la Inmunodeficiencia Humana (VIH) es considerada una prioridad política mundial y un problema de salud que ha originado devastadoras consecuencias desde 1981, año en el que se conocen los primeros casos de Síndrome de Inmunodeficiencia Adquirida (SIDA) en California y Nueva York, hasta nuestros días.

Según los datos obtenidos a nivel mundial en el año 2015, la prevalencia de personas infectadas por VIH fue de 36,7 millones de casos, con una incidencia de 2,1 millones de nuevas infecciones ese mismo año, aunque existen diferencias por regiones, dentro de cada país, entre sexo, por grupos de edad y entre poblaciones específicas. En muchos países la prevalencia del VIH es mayor en las ciudades, pues en ellas, los estilos de vida conllevan a tener mayores comportamientos de riesgo.

En este mismo año, la región con más incidencia y prevalencia de VIH fue África Oriental y Meridional, siendo los profesionales del sexo el mayor porcentaje de infectados. En esa área, las desigualdades de género, la pobreza y el escaso acceso a educación y a servicios sanitarios, suponen un gran riesgo de contagio de VIH en mujeres jóvenes y adolescentes, sin embargo, en Oriente Medio y África del Norte se obtuvieron las cifras más bajas de prevalencia e incidencia.

Según reportes de la Organización Mundial de la Salud (OMS), en 2015 el número de defunciones en adolescentes fue de 1,3 millones por causas relacionadas con VIH o SIDA, 


\section{Algunas consideraciones sobre el VIH/SIDA}

Vol. 2, núm. 4., (2018)

Vinicio Antonio López Del Valle; Guido Boanerges Troya Moscol; Nataly del Roció Varas Landivar; María Belén Guzmán Vega

cobrando gran importancia la enfermedad en adolescentes y población joven. (Mariscal Fuente \& Racionero Moreno, 2017)

El Programa Conjunto de las Naciones Unidas sobre el virus de la inmunodeficiencia humana/sida (VIH/sida), conocido como ONUSIDA, planteó que al cierre del 2016 existían 36,7 millones de personas vivían con el VIH en todo el mundo; y que de ellos correspondían 2 millones a América Latina y el Caribe; de igual forma, se registraron aproximadamente 100000 nuevas infecciones y 50000 fallecimientos por causas relacionadas con la enfermedad. (Besse Díaz, Romero García, Cobo Montero , Minier Pouyou, \& Esther Suárez, 2018)

Los adolescentes y jóvenes son grupos vulnerables de padecer est as infecciones, pues, aproximadamente 2500 se infectan diariamente con VIH debido a los peligros a que se exponen durante su transición a la edad adulta y la falta de conocimientos sobre el tema entre otros factores y conductas de riesgo a las que están expuestos.

Los jóvenes generalmente inician una vida sexual activa sin protección para prevenir estas infecciones. Son factores incidentes en la adquisición de la enfermedad, de tipo social: la ocupación y su estructura familiar; educativos: conocimiento sobre VIH/Sida, vías de transmisión, formas de contagio y participación en programas preventivos; y culturales: el tipo de religión, relaciones sexuales y el uso de preservativos; todos ellos contribuyen al aumento de riesgos de infección por VIH y de otras enfermedades de importancia en la salud pública. (RealCotto, González Fernández, Irrazabal Bohorquez, Ramírez Amaya, Roby-Arias, \& Hernández Navarro, 2017) 


\section{Algunas consideraciones sobre el VIH/SIDA}

Vol. 2, núm. 4., (2018)

Vinicio Antonio López Del Valle; Guido Boanerges Troya Moscol; Nataly del Roció Varas Landivar; María Belén Guzmán Vega

Se plantea que los nuevos contagios con el VIH ocurren a razón de 11 por min y que la mayoría ocurre en jóvenes entre 15 y 24 años de edad, siendo estos uno de grupos poblacionales más propensos a padecer esta afección.

Esta enfermedad origina grandes e irreparables estragos, no sólo entre quienes contraen la enfermedad o mueren por esa causa sino también entre sus familiares, comunidades y gobiernos. Esto se refleja en el número de huérfanos, los desequilibrios y traumas en las familias, el abatimiento de los trabajadores, la sobrecarga a los servicios de salud y en los sistemas sociales. (Ochoa Soto, 2004)

\section{Antecedentes.}

Los primeros casos de esta afección se describen en Los Ángeles, California al presentarse en cinco jóvenes homosexuales, estudiados en hospitales diferentes, neumonía por un germen oportunista: el protozoo Pneumocistis Carinii en mayo de 1980 y junio de 1981.

En junio del propio año aparecieron 26 casos de hombres homosexuales con Sarcoma de Kaposi asociado a otras infecciones oportunistas. Todas estas infecciones se acompañaban de una grave inmunodeficiencia y la mayoría aparecía en hombres homosexuales o drogadictos lo que hizo suponer que era producida por un germen que se transmitía por vía sexual o sanguínea y no es hasta 1982 que recibió el nombre de Síndrome de Inmunodeficiencia Adquirida. (Lamotte Castillo, 2004) 


\section{Algunas consideraciones sobre el VIH/SIDA}

Vol. 2, núm. 4., (2018)

Vinicio Antonio López Del Valle; Guido Boanerges Troya Moscol; Nataly del Roció Varas Landivar; María Belén Guzmán Vega

\section{Definición}

El Síndrome de lnmunodeficiencia Adquirida (SIDA), es una enfermedad infecto contagiosa producida por el Virus de lnmunodeficiencia Humana (VIH), que ataca el sistema de defensa de la persona, haciéndola susceptible a contraer cualquier enfermedad y causarle la muerte. (Anchi Chihua \& Franco Echevarría , 2015)

\section{Patogenia}

La enfermedad es producida por retrovirus los cuales son virus ARN que se replican mediante un $\mathrm{ADN}$ intermediario, que depende del $\mathrm{ADN}$ polimerasa o retrotranscriptasa, proveniente del ARN y que se encuentra dentro del virión. Este conjunto enzimático permite copiar o transcribir información genética de tipo ARN a ADN. Este proceso para sintetizar una partícula a partir de una información genética en forma de ARN, solo es atribuible a estos virus. Dentro de estos los que afectan al ser humano son el VIH 1 y 2, descubiertos en 1983 y 1986 respectivamente.

El virus VIH- 1 tiene varios serotipos y se clasifican en 3 grandes grupos: $\mathrm{M}$ (main), $\mathrm{O}$ (outlier) y $\mathrm{N}$ (New, No $\mathrm{M}$, No $\mathrm{O}$ ). El primero causa la mayoría de las infecciones que registradas a escala mundial y se conocen los serotipos siguientes: A, B, C, D, E, F, G, H, J, K.

Por su parte, el VIH-2, por ser de menor circulación mundial, tiene pocos serotipos: A, B, C y E.1-5. (Lamotte Castillo J. , 2014)

Vías de transmisión 


\section{Algunas consideraciones sobre el VIH/SIDA}

Vol. 2, núm. 4., (2018)

Vinicio Antonio López Del Valle; Guido Boanerges Troya Moscol; Nataly del Roció Varas Landivar; María Belén Guzmán Vega

Los virus que transmiten esta enfermedad están presentes en mayor concentración en la sangre infectada, semen, fluidos vaginales o leche materna. Este virus penetra en el organismo a través de las membranas mucosas del ano, la vagina, el pene (uretra), la boca, cortaduras, ampollas abiertas o lesiones de la piel.

Las vías de transmisión que se han demostrado son las siguientes:

1.- Transmisión Sexual.- Esta vía es la más frecuente donde se contrae el virus a través de la actividad sexual sin protección, siendo el sexo anal y vaginal los más riesgosos, aunque se señala que existe un pequeño número que va en aumento de casos reportados de transmisión del VI H por el medio del sexo oral. Con cada una de estas prácticas la pareja receptiva está en mayor riesgo. En sexo heterosexual, las mujeres corren mayor peligro de infectarse que los hombres, estas vías de infección por contacto sexual tanto en las relaciones anales, vaginales y buco genitales son las que cobran mayor número de víctimas. Es muy frecuente en hombre que tienen sexo con otros hombres.

2.- Transmisión Sanguínea. - El VIH cuando se transmite por vía sanguínea, se vehiculiza a través de transfusiones de sangre y hemoderivados. También se puede transmitir al compartir jeringas o agujas para inyectarse drogas, las personas que comparten las mismas pueden transmitir el virus en pequeñas cantidades de sangre que queden en la aguja o jeringa usada, pues, el uso común de jeringas es muy frecuente en los usuarios de drogas intravenosas. En el caso de la transfusión sanguínea o componentes hay abundantes pruebas que indican que la sangre y los productos hematológicos o el concentrado del factor VIII obtenidos de pacientes con SIDA lleven el agente causal, sin 


\section{Algunas consideraciones sobre el VIH/SIDA}

Vol. 2, núm. 4., (2018)

Vinicio Antonio López Del Valle; Guido Boanerges Troya Moscol; Nataly del Roció Varas Landivar; María Belén Guzmán Vega

embargo para que se transmita es necesario que la sangre infectada se introduzca directamente al torrente sanguíneo del receptor, que puede ser favorecida por pinchazos o heridas producidas por agujas u objetos que pinchen o corten y que hayan estado en contacto con sangre infectada.

3.-Transmisión Perinatal.- En la transmisión transplacentaria y/o perinatal se transmite de la madre al hijo en el embarazo, parto y lactancia. La transmisión se efectúa por distintos medios en relación al momento del contagio. Durante el embarazo se produce a través de la placenta. En el parto la rotura de la bolsa amniótica y el traumatismo del canal favorecen el contacto del feto con las secreciones genitales maternas. Si la madre está infectada y hay contacto directo de sus secreciones o de su sangre con mucosas y sangre fetal, la transmisión se efectúa en esta etapa. Durante la asistencia del parto las madres seropositivas, cuando en la ligadura y sección del cordón umbilical se exprime la sangre hacia el hijo, se aumenta la posibilidad de infectar al recién nacido. En el posparto la transmisión del HIV se efectúa frecuentemente mediante la leche materna, durante la lactancia. (Anchi Chihua \& Franco Echevarría , 2015)

\section{Fisiopatología}

El virus del VIH infecta especialmente a los linfocitos CD4 y los monocitos-macrófagos, lo que trae como consecuencia una depleción lenta y progresiva de dichos linfocitos a causa de la replicación viral dentro de ellos. Una vez que esta se inicia se inmortaliza en el tiempo. El organismo trata de reponer la mayoría de las células inmunológicas destruidas, pero nunca logra toda la cantidad que se destruyó. Por otra parte, las manifestaciones clínicas aparecerán cuando 


\section{Algunas consideraciones sobre el VIH/SIDA}

Vol. 2, núm. 4., (2018)

Vinicio Antonio López Del Valle; Guido Boanerges Troya Moscol; Nataly del Roció Varas Landivar; María Belén Guzmán Vega

el equilibrio se incline a favor de la destrucción y no de la reposición celular, de manera que lleva al agotamiento del sistema inmunológico. Lo anterior explica la razón por la cual el comienzo de la terapia antirretroviral se debe de iniciar antes de que aparezcan los primeros síntomas. El hecho de inmortalizar la infección desempeña un rol importante en los reservorios del virus como lo son: el cerebro, los ganglios linfáticos y células del sistema retículo endotelial. (Lamotte Castillo J. , 2014)

\section{Cuadro Clínico}

La infección por el VIH tiene varias fases clínicas, las cuales tienen sus manifestaciones. Ellas son:

\section{I.- Fase de infección aguda retroviral}

Esta fase puede ser asintomática como ocurre en la mayoría de los pacientes o sintomática donde se presenten múltiples síntomas. Esta fase se corresponde con la llegada del virus al organismo.

Entre los síntomas que puede producir tenemos:

1. Generales: fiebre, faringitis, linfadenopatías -- cuadro parecido al de la mononucleosis infecciosa--, artralgias, mialgias, anorexia y pérdida de peso.

2. Dermatológicos: erupción eritematosa maculopapular, urticaria difusa y alopecia.

3. Gastrointestinales: náuseas, vómitos, diarrea y ulceraciones mucocutáneas.

4. Neurológicos: cefalea, dolor retroorbitario, meningoencefalitis, neuropatía periférica, radiculitis y síndrome de Guillain-Barré. 


\section{Algunas consideraciones sobre el VIH/SIDA}

Vol. 2, núm. 4., (2018)

Vinicio Antonio López Del Valle; Guido Boanerges Troya Moscol; Nataly del Roció Varas Landivar; María Belén Guzmán Vega

De forma general, estos síntomas son inespecíficos y tienen un período de 6 a 8 semanas aproximadamente y no requieren tratamiento específico, solo sintomático, es frecuente que médicos y pacientes no les den importancia y a su vez sea difícil determinar con exactitud la frecuencia de este cuadro agudo. Durante esta fase existe el inconveniente de que la serología del VIH es negativa, aunque los antígenos virales sean positivos.

\section{Fase asintomática de la infección por VIH u oportunistas menores}

Esta fase puede tener una duración promedio entre uno y 8,5 años, aunque con los nuevos tratamientos puede durar más tiempo, esta fase es la de portador asintomático.

De forma general, puede estar asintomático por completo o presentar un síndrome adénico con las características siguientes: más de 3 meses de evolución, con ganglios firmes pero no leñosos, móviles, no dolorosos, sin cambios en la piel que los recubre y que ocupan 2 o más regiones contiguas. Se llama linfadenopatía generalizada persistente, puede haber esplenomegalia o no y el diagnóstico en esta fase es por medio de la serología VIH, por lo cual es importante estimular por todas las vías posibles que las personas se interesen por saber su seroestatus.

\section{Fase sintomática de la infección por VIH u oportunistas menores}

Esta fase es la intermedia entre la de portador asintomático y el caso sida o final. $\mathrm{Su}$ duración depende de diferentes factores, entre los cuales figuran: tipo de cepa viral infectante y respuesta inmunológica del huésped, entre otros. 


\section{Algunas consideraciones sobre el VIH/SIDA}

Vol. 2, núm. 4., (2018)

Vinicio Antonio López Del Valle; Guido Boanerges Troya Moscol; Nataly del Roció Varas Landivar; María Belén Guzmán Vega

Aparecen los primeros síntomas o se presentan enfermedades relacionadas con una inmunodeficiencia subyacente, de modo que estos pacientes ya no estarán tan bien como en la fase anterior, pero los problemas no serán tan graves como en la siguiente.

Clínicamente se caracteriza por distintos síntomas. Entre ellos se encuentran:

1.- Generales: malestar general, astenia persistente, síndrome febril prolongado, acompañado de sudoración nocturna y pérdida de peso que puede llegar a 10\%. 2.Hematológicos: anemia y trombocitopenia, con síndrome purpúrico o sin él.

3.- Linfadenopáticos: pueden disminuir los ganglios linfáticos

4.- Respiratorios: tos seca persistente

5.- Digestivos: diarrea que puede durar más de un mes

6.- Dermatológicos: candidiasis bucal, dermatitis seborreica, herpes simple recidivante (anal o genital), herpes zóster y verrugas genitales

7.- Neurológicos: polineuropatía, síndrome ansioso depresivo y meningitis aséptica.

\section{Fase sida u oportunistas mayores}

Es el estadio final de la infección por VIH y se caracteriza por la aparición de infecciones oportunistas y tumores raros. Desde el punto de vista inmunológico, representa una inmunodepresión severa, con una depleción notable del número de linfocito CD4, cuya función en la respuesta inmune es bien conocida. Hay una alta replicación viral, favorecida por la 


\section{Algunas consideraciones sobre el VIH/SIDA}

Vol. 2, núm. 4., (2018)

Vinicio Antonio López Del Valle; Guido Boanerges Troya Moscol; Nataly del Roció Varas Landivar; María Belén Guzmán Vega

debilidad del sistema inmunológico. Desde el punto de vista clínico, se considera que un paciente es un posible caso sida cuando tiene varias afecciones oportunistas mayores que así lo indiquen.

Actualmente, además de las enfermedades indicadoras de sida, también se ha incluido el término sida inmunológico, el cual incluye a pacientes con número de células CD4 menor de 200 mm3 y clínicamente asintomático; también se ha incluido en la práctica clínica el término “debut" sida para todos aquellos casos que al momento de ser detectados tienen alguna enfermedad oportunista definitoria de sida o CD4 por debajo de 200 células. Estos casos, al ser diagnosticado en esta fase tan avanzada de la infección, se asocian con una alta mortalidad por poca respuesta a la terapia antirretroviral, reacciones adversas, irreversibilidad de la infección oportunista que tenga en ese momento, así como dificultad para lograr la recuperación del sistema inmunológico. (Lamotte Castillo J. , 2014)

\section{Diagnóstico.}

Las pruebas de laboratorio que se utilizan para diagnosticar la infección por retrovirus humanos se clasifican en directas e indirectas.

\section{Pruebas directas}

Entre estas se encuentran la antigenemia P24, cultivo vira y reacción en cadena de la polimerasa. Estas 2 últimas se utilizan para el diagnóstico de la infección en los niños junto con el western blot, por la transferencia pasiva de anticuerpos de la madre al recién nacido. 


\section{Algunas consideraciones sobre el VIH/SIDA}

Vol. 2, núm. 4., (2018)

Vinicio Antonio López Del Valle; Guido Boanerges Troya Moscol; Nataly del Roció Varas Landivar; María Belén Guzmán Vega

Estas facilitan el diagnóstico precoz de la infección, pues permiten detectar la presencia del virus o de sus constituyentes (proteínas y ácido nucleico) aun antes de desarrollarse la respuesta de anticuerpos frente a ellos, pero tienen el inconveniente de ser muy costosas.

\section{Pruebas indirectas}

Estas pruebas serológicas son de varios tipos:

1. Prueba de screening (despistaje). Serología VIH (ELISA o micro ELISA)

2. Prueba confirmatoria. Serología western blot

3. Pruebas suplementarias

Demuestran la respuesta inmune por parte del huésped y están basadas en pruebas serológicas para la detección de anticuerpos en el suero. La presencia de anticuerpos antiVIH, lejos de reflejar una exposición y erradicación inmune del virus en el pasado, significa el estado de portador actual.

Prueba de diagnóstico rápido de la infección por VIH (Hexagón)

Hoy día se cuenta con la posibilidad de un diagnosticador que permite conocer presuntivamente si la persona tiene infección por VIH o no. Este constituye una herramienta útil para perfeccionar el diagnóstico y la atención a grupos vulnerables, así como fortalecer la vigilancia epidemiológica en situaciones, lugares y grupos poblacionales específicos. Es de fácil aplicación, alta sensibilidad y especificidad y su desempeño ha sido probado con paneles bien caracterizados, pero esta tiene que ser confirmada con las técnicas anteriormente descritas y 


\section{Algunas consideraciones sobre el VIH/SIDA}

Vol. 2, núm. 4., (2018)

Vinicio Antonio López Del Valle; Guido Boanerges Troya Moscol; Nataly del Roció Varas Landivar; María Belén Guzmán Vega

seguir el algoritmo diagnóstico establecido nacionalmente. A pesar de esto, es de gran utilidad en la práctica clínica, donde hay que tomar decisiones cuando está en peligro la vida del paciente como es el caso de los debuts clínicos o en caso de accidente ocupacional para saber el seroestatus de la fuente.

- Radioinmunoanálisis

- Inmunofluorescencia

Estas sólo se reservan para casos que no estén bien definidos por los métodos anteriores, a pesar de su especificidad.

\section{Exámenes complementarios para el seguimiento evolutivo de pacientes con VIH}

Para conocer la evolución de la infección por VIH y determinar el grado de inmunodepresión se utilizan las pruebas siguientes:

\section{Pruebas para medir el nivel de replicación viral}

Carga viral: determina la cantidad de ARN viral presente en un mililitro de sangre y se mide en logaritmo. Valores > 10000 o 20000 copias (depende del método utilizado), denotan alta replicación viral y grandes probabilidades de progresión al sida. Se debe realizar una determinación al momento del diagnóstico de esta infección y luego, una vez al año, a los pacientes que toman la terapia antirretroviral, ya que representa el principal indicador de respuesta al tratamiento. El resultado deseado de esta prueba es hacerla indetectable, es decir, que las cifras mínimas de detección del virus tengan menos de 40 copias/mL, o menos, en dependencia del equipo que se utilice. 


\section{Algunas consideraciones sobre el VIH/SIDA}

Vol. 2, núm. 4., (2018)

Vinicio Antonio López Del Valle; Guido Boanerges Troya Moscol; Nataly del Roció Varas Landivar; María Belén Guzmán Vega

2. Pruebas para medir el nivel inmunológico del huésped frente al virus. Conteo de leucocitos CD4

Valor normal 500 células o más, lo que equivale a $29 \%$ o más. Según progresa la infección estas células disminuyen de forma progresiva y mantenida, aunque sin mucha expresión desde el punto de vista clínico en los estadios iniciales. Para los pacientes en la fase asintomática, se deben realizar 2 veces al año y para los que toman la terapia antirretroviral, cada 3 meses. Es el principal elemento a tener en cuenta para decidir el inicio de la terapia antirretroviral.1,5,18

- Prueba cutánea de la tuberculina: presencia de anergia cutánea según avanza la inmunodepresión.

- Hemograma: aparece una anemia a medida que la enfermedad progresa o puede ser como reacción adversa del uso de los antirretrovirales como la zidovudina.

- Eritrosedimentación: se acelera según empeora la enfermedad o el paciente tenga alguna infección oportunista asociada.

3. Pruebas para determinar la repercusión de la infección y de los tratamientos en los diferentes órganos y sistemas

- Radiografía de tórax: para detectar neumopatías inflamatorias y/o tuberculosis

- Radiografía de senos perinasales: determina la presencia o no de sinusitis, sobre todo maxilar. 


\section{Algunas consideraciones sobre el VIH/SIDA}

Vol. 2, núm. 4., (2018)

Vinicio Antonio López Del Valle; Guido Boanerges Troya Moscol; Nataly del Roció Varas Landivar; María Belén Guzmán Vega

- Pruebas de función hepática: elevación de las transaminasas por los medicamentos o por la confección con virus de las hepatitis B y C.

- Heces fecales: para buscar parásitos.

- Ecografía abdominal: para observar la presencia o no de alteraciones hepáticas, adenopatías centrales y alteraciones renales, incluyendo litiasis, principalmente en los pacientes tratados con indinavir.

- Serología: para determinar infección asintomática (sífilis, hepatitis B, hepatitis C, toxoplasmosis, Cytomegalovirus, micológicas).

- Punción lumbar: para descubrir una infección en el sistema nervioso central.

- Tomografía axial computarizada de cráneo: para detectar un tumor o lesión que ocupa espacio en el sistema nervioso central, como el absceso cerebral y la atrofia cerebral asociada a la demencia por sida.

- Endoscopia: para detectar una posible gastroduodenitis crónica y/o infiltración del aparato digestivo por neoplasias como el sarcoma de Kaposi, el linfoma no Hodkin o enteritis por VIH.

- Glucemia, prueba de tolerancia a la glucosa: para detectar los trastornos de la glucemia que se presentan en estos pacientes, atribuible al uso de los antirretrovirales, principalmente los inhibidores de proteasas.

- Lipidograma, principalmente colesterol y triglicéridos: demuestra las alteraciones de estas grasas, las cuales pueden estar asociadas al uso del tratamiento antirretroviral, principalmente los inhibidores de proteasas y otros, como consecuencia de las alteraciones metabólicas que produce el propio virus en la persona infectada. 


\section{Algunas consideraciones sobre el VIH/SIDA}

Vol. 2, núm. 4., (2018)

Vinicio Antonio López Del Valle; Guido Boanerges Troya Moscol; Nataly del Roció Varas Landivar; María Belén Guzmán Vega

- Pruebas de función renal como microalbuminuria, cituria, creatinina y urea: son de vital importancia, ya que de forma temprana revelan el daño renal en el curso de esta infección, de manera que permite diagnosticar oportunamente la nefropatía por VIH.

- Prueba de HLA- B*5701: para determinar de ser positivo, la posible reacción alérgica si el paciente toma el antirretroviral abacavir. No se recomienda en estos casos. También se realiza la determinación de tropismo celular de correceptor para determinar el predomino del correceptor CCR5 y así poder incluir en la combinación de antirretrovirales el inhibidor de este.

\section{Complicaciones}

La infección por VIH ocasiona complicaciones en todos los aparatos y sistemas, es decir, sus complicaciones son multisistémicas pero los más afectados son el respiratorio, el digestivo y el Sistema Nervioso Central. Entre las más sobresalientes por sistemas figuran:

- Respiratorias: neumonía por Pneumocistis Jirovesi, tuberculosis pulmonar y sinusitis repetidas

- Digestivas: cuadro diarreico crónico, enteropatía por VIH y disfagia

- Neurológicas

a) Por infección primaria del VIH: encefalitis por VIH (demencia por sida y atrofia cerebral), meningitis aséptica típica y mielopatía vascular

b) Por infecciones asociadas a la inmunodepresión: meningoencefalitis por Cryptococcus neoformans, neurotoxoplasmosis y lesiones tumorales por papilomavirus 


\section{Algunas consideraciones sobre el VIH/SIDA}

Vol. 2, núm. 4., (2018)

Vinicio Antonio López Del Valle; Guido Boanerges Troya Moscol; Nataly del Roció Varas Landivar; María Belén Guzmán Vega

Procesos tumorales asociados al VIH: sarcoma de Kaposi, linfoma no Hodgkin y linfoma primario del sistema nervioso central

Otras de las complicaciones que deben tenerse en cuenta son: Wasting disease, leucoplasia vellosa bucal, herpes zóster, multidermatoma, candidiasis bucal, dermatitis seborreica e hiperpigmentación cutánea, trombocitopenia asociada al VIH, nefropatía por VIH y otras.

\section{Tratamiento}

Actualmente no se cuenta con un tratamiento para curar esta infección, pero se ha logrado, mediante el cumplimiento de varias acciones de salud, encabezadas por el tratamiento antirretroviral, que los pacientes con VIH/sida vivan muchos años y con una buena calidad de vida. Entre dichas acciones figuran:

\section{Tratamientos antirretrovirales}

El objetivo es disminuir la replicación del virus hasta niveles indetectables, lograr la restauración del sistema inmunológico y hacerlo más inmunocompetente. El principal criterio que se tiene en cuenta para iniciar esta terapia es determinar el número de linfocitos CD4, pero actualmente se van definiendo cada vez mejor los criterios para comenzar este tratamiento.

¿Cuándo se debe iniciar la terapia antirretroviral?

- Antecedente de una enfermedad definitoria de sida 


\section{Algunas consideraciones sobre el VIH/SIDA}

Vol. 2, núm. 4., (2018)

Vinicio Antonio López Del Valle; Guido Boanerges Troya Moscol; Nataly del Roció Varas Landivar; María Belén Guzmán Vega

- Linfocitos CD4 con menos de 200 células

- Linfocitos CD4 entre 200-350 células

- Mujeres embarazadas, independientemente del número de linfocitos CD4

- Pacientes con nefropatía por VIH

- Pacientes con coinfección VIH/virus de la hepatitis B o C

- Carga viral mayor de 100000 UI, independientemente del número de linfocitos CD4

- Disminución rápida de linfocitos CD4 (más de 100 células por año)

- Riesgo elevado de enfermedad cardíaca

- Porcentaje de CD4: menos de 14

- Edad: más de 55 años

- En este caso siempre se trata de complementarlo con otro criterio

- Linfocitos CD4 +: más de 350 células y menos de 500

En cuanto a este último criterio, hoy día, los expertos que se encuentran a favor y en contra están divididos por los elementos positivos y negativos al respecto. En Cuba, no se utiliza dicho criterio.

El tratamiento antirretroviral está basado en la combinación de, al menos, 3 medicamentos que actúan en diferentes puntos del ciclo de replicación del virus del VIH y es lo se conoce como terapia antirretroviral sumamente activa, en el caso de añadirse un cuarto medicamento se dice que es una megaterapia antirretroviral. 


\section{Algunas consideraciones sobre el VIH/SIDA}

Vol. 2, núm. 4., (2018)

Vinicio Antonio López Del Valle; Guido Boanerges Troya Moscol; Nataly del Roció Varas Landivar; María Belén Guzmán Vega

Cabe resaltar que una pobre respuesta en el aumento de los niveles de linfocitos CD4, pero con una adecuada supresión viral, no significa que ha fallado la combinación terapéutica en el paciente y que deba cambiarse. (Lamotte Castillo J. , 2014)

\section{Conclusiones.}

El VIH/SIDA constituye una enfermedad infectocontagiosa viral que origina complicaciones multiorgánicas, causadas por una inunodepresión, siendo la vía de transmisión más común la sexual y que hasta estos momentos no existe tratamiento curativo de la misma, constituyendo la prevención el arma más eficaz para combatirla.

\section{Bibliografía.}

Anchi Chihua, E., \& Franco Echevarría , N. (2015). Nivel de conocimientos de los adolecentes sobre medidas preventivas del VIH-SISA en la I.E Señor de los Milagros de Ayacucho Mayo -Noviembre 2015.

Besse Díaz, R., Romero García, L., Cobo Montero , E., Minier Pouyou, L., \& Esther Suárez, E. (2018). Enfoque clínico y epidemiológico de pacientes con VIH/sida atendidos en un servicio de urgencias y emergencias. Recuperado el 3 de septiembre de 2018, de MEDISAN; 22(7): http://medisan.sld.cu/index.php/san/article/view/1753

Lamotte Castillo, J. (2004). Infección -enfermedad por VIH-SIDA. Recuperado el 3 de septiembre de 2018, de http://www.bvs.sld.cu/revistas/san/vol8_4_04/san06404.pdf

Lamotte Castillo, J. (2014). Infección por VIH/SIDA en el mundo actual. Recuperado el 3 de septiembre de 2018, de MEDISAN;18(7): https://scholar.google.com.cu/scholar?hl=es\&as_sdt=0\%2C5\&q=Infecci\%C3\%B3n+por +VIH\%2Fsida+en+el+mundo+actual\&btnG=

Mariscal Fuente, M., \& Racionero Moreno, E. (2017). Conocimiento, prácticas,actitudes y percepciones de riesgo frente al VIH/SIDA en estudiantes de Enfermería de la Universidad Autónoma de Madrid. Recuperado el 31 de agosto de 2018, de Trabajo fin 


\section{Algunas consideraciones sobre el VIH/SIDA}

Vol. 2, núm. 4., (2018)

Vinicio Antonio López Del Valle; Guido Boanerges Troya Moscol; Nataly del Roció Varas Landivar; María Belén Guzmán Vega

de grado : Proyecto de Investigación Universidad Autónoma de Madrid.Curso Académico 2016-2017: https://repositorio.uam.es/bitstream/handle/10486/.../mariscal_fuentes_mariatfg.pdf

Ochoa Soto, R. (2004). VIH-SIDA. Recuperado el 2 de septiembre de 2018, de Revista Cubana $\begin{array}{llll}\text { de Higiene } & \text { y }\end{array}$ http://scielo.sld.cu/scielo.php?script=sci_arttext\&pid=S156130032004000200001\&lng=es\&tlng=es.

Real-Cotto, J., González Fernández, J., Irrazabal Bohorquez, A., Ramírez Amaya, J., RobyArias, A., \& Hernández Navarro , M. (2017). Conocimientos sobre el VIH-SIDA en estudiantes de Odontologia de la Universidad de Guayaquil. Recuperado el 27 de agosto de 2018 , de EDUMECENTRO ;9(4). 